\title{
Mechanism of Oxytetracycline Removal by Coconut Shell Biochar Loaded with Nano-Zero-Valent Iron
}

\author{
Qi Li *, Siyu Zhao and Yuhang Wang
}

Citation: Li, Q.; Zhao, S.; Wang, Y Mechanism of Oxytetracycline Removal by Coconut Shell Biochar Loaded with Nano-Zero-Valent Iron. Int. J. Environ. Res. Public Health 2021, 18, 13107. https://doi.org/ 10.3390/ijerph182413107

Academic Editors: Yunhui Zhang, Fan Yang and Xiao Yang

Received: 6 November 2021

Accepted: 10 December 2021

Published: 12 December 202

Publisher's Note: MDPI stays neutral with regard to jurisdictional claims in published maps and institutional affiliations.

Copyright: (c) 2021 by the authors. Licensee MDPI, Basel, Switzerland. This article is an open access article distributed under the terms and conditions of the Creative Commons Attribution (CC BY) license (https:// creativecommons.org/licenses/by/ $4.0 /$ )
College of Urban and Environmental Sciences, Northwest University, Xi'an 710127, China; 201931906@stumail.nwu.edu.cn (S.Z.); yuhangwang895@stumail.nwu.edu.cn (Y.W.)

* Correspondence: qili726@nwu.edu.cn

\begin{abstract}
In this paper, coconut shell biochar (BC), pickling biochar (HBC), and nano-zero-valent ironloaded biochar (nZVI-HBC) were prepared; these were used to remove oxytetracycline (OTC), and the removal mechanism and degradation product were analyzed. These biochars were characterized using SEM, XRD, FTIR, and XPS. The effects of biochar addition amount, pH, ion type, and ion concentration on OTC adsorption were studied by a batch adsorption experiment. Under the optimal conditions, the equilibrium adsorption capacity of nZVI-HBC to OTC was $196.70 \mathrm{mg} \cdot \mathrm{g}^{-1}$. The adsorption process can be described by Langmuir isothermal adsorption equations, conforming to the pseudo-second-order dynamics model, indicating that adsorption is dominated by singlemolecule chemical adsorption, and a spontaneous process of increasing heat absorption entropy. Mass spectrometry showed that the OTC removal process of nZVI-HBC included not only adsorption but also degradation. These results provide a practical and potentially valuable material for the removal of OTC.
\end{abstract}

Keywords: biochar; oxytetracycline; nano-zero-valent iron; adsorption; degradation

\section{Introduction}

In recent years, with the rapid development of aquaculture, the pollution of antibiotics in the water environment has become increasingly more serious [1,2]. Due to the complex molecular structure and numerous intermediate products of antibiotics, they can be harmful to biological health [3,4]. Among them, oxytetracycline (OTC) is one of the most widely used veterinary antibiotics; aquaculture wastewater constantly enters the environment and gradually accumulates, where long-term exposure can disrupt the balance of the ecosystems, leading to pathogenic microorganisms developing resistance $[5,6]$. Some research data show that OTC excreted through feces and urine remains bioactive, and over $90 \%$ is not metabolized. Today, more than $70 \%$ of OTC products end up in the environment after treatment at wastewater treatment plants [7]. According to the survey, OTC is widely used in veterinary medicine and food production, accounting for $70 \%$ of the consumption of antibiotics in Europe in 2017. Moreover, the OTC concentration detected in Chinese aquaculture was $315-15,163 \mathrm{ng} \cdot \mathrm{L}^{-1}[8,9]$. However, the traditional water pollution removal methods have no noticeable removal effect on antibiotics such as OTC. Therefore, it is necessary to find a suitable way to remove aquaculture wastewater.

At present, there are several methods for the removal of antibiotics, such as adsorption [10,11], biological treatment [12], biodegradation [13], membrane separation [14], and oxidation [15]. Zhou et al. reported that the $\mathrm{MnO}_{2} / \mathrm{UIO}-66$ composites prepared through an advanced oxidation process have great potential for application in the degradation removal of OTC [16]. Hadki et al. used the reduction of boron oxide graphene (B-rGO) to remove OTC, and in the first ten minutes, the removal rate could reach more than $85 \%$ [17]. Lian et al. used $\mathrm{FeO}_{\mathrm{n}}(\mathrm{OH})_{\mathrm{m}}$-modified oyster shell powder for OTC conversion. The effect was more than $81.5 \%$ [18]. Jia et al. used the coconut shell biochar adsorption of OTC in aqueous solutions, and the results showed that the maximum adsorption rate of OTC 
reached $1667 \mathrm{mg} \cdot \mathrm{kg}^{-1}$ [19]. Among them, the adsorption method has widely been used because of its advantages of being a simple process, no secondary pollution, a comprehensive source of adsorbent, and so on. Biochar, as a new adsorbent, is characterized by large specific surface area, rich surface functional groups, and mineral compounds, making it widely used in the removal of antibiotics in the water environments. Currently, some domestic and foreign scholars have used biochar to research the removal and degradation of antibiotics in the natural environment [20]. Compared with other biochar raw materials, coconut shell has the largest surface area and porosity. Meanwhile, the coconut shell has the advantages of low ash content, high density, and high mechanical strength, making it suitable as a raw material for the adsorption of pollutants [21,22]. Shen et al. reported that coconut shell biochar has a good removal effect on $\mathrm{Cr}$ (VI) due to its rich functional groups [23]. Moreover, coconut shell biochar as an improver for fixing heavy metals in contaminated soil can improve the physical and chemical properties of soils [24]. Coconut shell biochar and quartz sand as composite adsorbents can adsorb Mn with a high removal efficiency of $94.22 \%$ [25]. Therefore, coconut shell has many advantages, and it is selected as the raw material of biochar.

Nano-zero-valent iron (nZVI) refers to zero-valent iron particles with a particle size of 1-100 nm, which are characterized by small particle size, strong reducibility, large sur-face area, and strong transferability, etc. Thus, nZVI has good application prospects in the removal of water pollutants [26]. The research shows that nZVI has a good removal effect on antibiotics [27], heavy metals [28], and inorganic salts. However, nZVI has some limitations because of its characteristics, and the modification of nZVI is also one of the standard methods used by many researchers [29]. Among them, the carrier load [30,31] is one of the simple methods for the modification of nZVI. The carrier generally selects materials with abundant sources and a low price of chromium, which ensures the processing effect and controls the cost. It also has good prospects for application in industrial production [32].

In this paper, coconut shell was used as a raw material of biochar, coconut shell biochar (BC) was prepared, it was modified by hydrochloric acid (HBC), and nZVI was loaded on HBC by the liquid-phase reduction method (nZVI-HBC). At the same time, the OTC was removed in the batch adsorption experiment, and its adsorption properties of different materials were compared. Combined with material characterization, the adsorption mechanism of pollutants by different modification methods was explored, and the possible mechanism and other intermediates in the degradation process were analyzed. nZVI was loaded on the basis of modified biochar, which provided an efficient and economic treatment method for OTC removal and a reference for aquaculture wastewater.

\section{Materials and Methods}

\subsection{Materials and Reagent}

The coconut shell was collected from a planting base in Hainan, China. OTC (analytical grade, purity $>99 \%$ ) was from Shanghai Source Biological Technology Co. Ltd., Shanghai, China. All reagents in this work were of analytical-grade purity and above and were bought from Comiou Chemical Reagent Co. Ltd., Tianjin, China. All ultrapure water used in the experiments had a resistivity of $18.2 \mathrm{M} \Omega$.

\subsection{Analytical Instruments and Methods}

The surface structure and morphology of the samples were analyzed using a scanning electron microscope (FEI Quenta 400 FEG, Hillsboro, OR, USA). An X-ray diffraction analyzer (Rigaku Corporation, Rigaku MiniFlex II, Tokyo, Japan) was applied to investigate the crystalline structure of biochar. The chemical properties of biochar were highlighted by a Fourier-transform infrared spectrometer (Nicolet Instruments, Nexus870, Madison, WI, USA). X-ray photoelectron spectroscopy (Rigaku Corporation, Rigaku MiniFlex II, Tokyo, Japan) was used to determine the elemental quantification and valence analysis in ferrocarbon. 
The content of OTC was determined by an ultraviolet spectrophotometer (Shimadzu Corporation, UV-1800, Tokyo, Japan) with a maximum absorption wavelength of $268 \mathrm{~nm}$ [33]. The degradation products of OTC were determined by LC-MS (Agilent Technologies, Agilent 6460C, Santa Clara, CA, USA).

\subsection{Experimental Method}

Material Preparation

The preparation of the $\mathrm{BC}$ : The coconut shells were placed in the crucible and placed in the muffle furnace to heat at a rate of $5^{\circ} \mathrm{C} \cdot \mathrm{min}^{-1}$ to $800^{\circ} \mathrm{C}$ for $2 \mathrm{~h}$. After the thermolysis, it was cooled to room temperature, and after passing 100 mesh sieves $(<0.150 \mathrm{~mm})$ in a sealed bag, it was recorded as $\mathrm{BC}$.

The preparation of the $\mathrm{HBC}$ : $\mathrm{BC}$ was soaked in $1 \mathrm{~mol} \cdot \mathrm{L}^{-1}$ of $\mathrm{HCl}$ for $24 \mathrm{~h}$, repeatedly cleaned to neutral with deionized water, dried for $24 \mathrm{~h}$ in a drying oven at $80^{\circ} \mathrm{C}$, and stored in a sealed bag, denoted as HBC.

The preparation of the nZVI-HBC: First, $0.56 \mathrm{~g}$ of HBC was placed in a three-neck flask, $100 \mathrm{~mL}$ of $\mathrm{FeSO}_{4} \cdot 7 \mathrm{H}_{2} \mathrm{O}$ ethanol-water solution (ethanol: water $=3: 7$ ) was added, $2 \mathrm{~mL}$ of polyethylene glycol solution was dropped, and it was stirred for $30 \mathrm{~min}$. Then, under the existence of nitrogen, $0.5 \mathrm{~mol}$ of $\mathrm{NaBH}_{4}$ was dropped into the solution and stirred violently. After the reaction was completed, stirring continued for $1 \mathrm{~h}$ to produce modified biochar load nZVI (nZVI-HBC) [34]. nZVI-HBC was adsorbed with magnets and washed with deoxygenated high-purity water and anhydrous ethanol 3 times. It was placed in a the vacuum drying oven at $60^{\circ} \mathrm{C}$ for $24 \mathrm{~h}$, and then stored in a brown bottle for backup.

\subsection{Batch Adsorption Experiment}

Experiment 1: Effect of biochar addition amount on OTC removal rate. Biochar was added to an OTC solution with an initial mass concentration of $20 \mathrm{mg} \cdot \mathrm{L}^{-1}$ and a volume of $50 \mathrm{~mL}$ in the proportion of 2, 4, 6, 8, 10, 15, and $20 \mathrm{mg}$. A conical flask was placed in a constant-temperature oscillating chamber, and then it oscillated at a frequency of $150 \mathrm{r} \cdot \mathrm{min}^{-1}$ at $(25 \pm 1){ }^{\circ} \mathrm{C}$ for $24 \mathrm{~h}$ in the dark. The liquid was taken after filtering by a $0.22 \mu \mathrm{m}$ membrane sample, the concentration of OTC solution in the remaining solution was determined using ultraviolet spectrometry, and the average was repeated three times.

Experiment 2: Effect of different initial $\mathrm{pH}$ values on OTC removal rate. Here, $6 \mathrm{mg}$ of biochar was placed in a conical flask, and added with $20 \mathrm{mg} \cdot \mathrm{L}^{-1}$ and a volume of $50 \mathrm{~mL}$ of OTC solution was added. The $\mathrm{pH}$ was adjusted to 3.0, 5.0, 7.0, 9.0, and 11.0 using $\mathrm{HCl}$ or $\mathrm{NaOH}$. The other settings were the same as experiment 1 , and the average was repeated three times.

Experiment 3: Effect of ion type on OTC removal rate. Keeping the other conditions unchanged, $0.2 \mathrm{~mol} \cdot \mathrm{L}^{-1}$ of $\mathrm{NaCl}, \mathrm{KCl}, \mathrm{MgCl}_{2}, \mathrm{CaCl}_{2}, \mathrm{NaNO}_{3}, \mathrm{NaHCO}_{3}$, and $\mathrm{Na}_{2} \mathrm{CO}_{3}$ solution were prepared. The other settings were the same as experiment 1 , and the average was repeated three times.

Experiment 4: Effect of ion concentration on OTC removal rate. Keeping the other conditions unchanged, the ionic strength of solution was adjusted by different concentrations of $\mathrm{NaCl}$ solution $\left(0.00,0.05,0.10,0.20\right.$, and $\left.0.50 \mathrm{~mol} \cdot \mathrm{L}^{-1}\right)$. The other settings were the same as experiment 1 , which was repeated three times to average.

\subsection{Isothermal Adsorption}

The initial OTC solution concentrations were set as $5,10,20,30,40$, and $50 \mathrm{mg} \cdot \mathrm{L}^{-1}$, and biochar was added to different concentrations of OTC solutions. The conical flasks were placed in a constant-temperature shock chamber at $15^{\circ} \mathrm{C}, 25^{\circ} \mathrm{C}$, and $35^{\circ} \mathrm{C}$, and then shaken at a frequency of $150 \mathrm{r} \cdot \mathrm{min}^{-1}$ for $24 \mathrm{~h}$. The liquid was then taken after filtering by a $0.22 \mu \mathrm{m}$ membrane sample, and the samples were measured. The concentration of OTC solution in the remaining solution was determined by ultraviolet spectrometry. The experiment was repeated three times, and the average value was taken. The experimental 
results were fitted by the Langmuir isothermal adsorption model, Freundlich isothermal adsorption model, and Temkin isothermal adsorption model [35].

$$
\begin{gathered}
\text { Langmuir isothermal adsorption model : } q_{e}=\frac{q_{m} K_{L} C_{e}}{1+K_{L} C_{e}} \\
\text { Freundlich isothermal adsorption model : } q_{e}=K_{F} C_{e}^{\frac{1}{n}} \\
\text { Temkin isothermal adsorption model : } q_{e}=\left(\frac{R T}{b}\right) \ln K_{T}+\left(\frac{R T}{b}\right) \ln C_{e}
\end{gathered}
$$

where $q_{e}$ and $\mathrm{Ce}$ are, respectively, the adsorption amount and concentration of pollutants in the solution when the adsorption of contaminants by the adsorbent reaches equilibrium, $\mathrm{mg} \cdot \mathrm{g}^{-1}$ and $\mathrm{mg} \cdot \mathrm{g}^{-1}$, respectively; $q_{m}$ is the maximum adsorption capacity, $\mathrm{mg} \cdot \mathrm{g}^{-1}$; $K_{L}, K_{F}$, and $K_{T}$ are dimensional constants of Langmuir, Freundlich, and Temkin models, $\mathrm{L} \cdot \mathrm{mg}^{-1}, \mathrm{~L} \cdot \mathrm{mg}^{-1}$, and $\mathrm{L} \cdot \mathrm{g}^{-1}$, respectively; $1 / n$ is an experience constant with no gauge. $R$ $\left(8.314 \times 10^{-3} \mathrm{~kJ} \cdot \mathrm{mol}^{-1} \cdot \mathrm{K}^{-1}\right)$ is the ideal gas constant, and $T$ is the absolute thermodynamic temperature, $K$.

\subsection{Adsorption Kinetics}

Keeping the other conditions unchanged, the conical flask was placed in a constanttemperature shock chamber, and then the samples were taken at 5, 10, 15, 30, 60, 120, $180,300,480,720,1440,2160$, and $2880 \mathrm{~min}$ of the shock at a frequency of $150 \mathrm{r} \cdot \mathrm{min}^{-1}$ without light. The supernatant was filtered by a $0.22 \mu \mathrm{m}$ filter membrane, and ultraviolet spectrometry was used to determine the concentration of OTC solution; the experiment was repeated three times to average. The experimental results were fitted by the pseudo-firstorder dynamics model [36], pseudo-second-order dynamics model [37], and intra-particle diffusion model [38-40].

$$
\begin{gathered}
\text { pseudo - first }- \text { order dynamics model : } q_{t}=q_{e}\left(1-e^{-k_{1} t}\right) \\
\text { pseudo - sec ond }- \text { order dynamics model }: q_{t}=\frac{k_{2} q_{e}^{2} t}{1+k_{2} q_{e} t} \\
\text { Intra - particle diffusion model }: q_{t}=k_{3} t^{0.5}+C
\end{gathered}
$$

where $t$ is the adsorption time, $\min ; q_{t}$ and $q_{e}$ are the adsorption capacities at $t$ and equilibrium, respectively, $\mathrm{mg} \cdot \mathrm{g}^{-1}, \mathrm{mg} \cdot \mathrm{g}^{-1} ; K_{1}, K_{2}$, and $K_{3}$ are, respectively, the pseudo-first-order, pseudo-second-order, and intra-particle diffusion dynamics rate constants, $\mathrm{g} \cdot \mathrm{mg}^{-1} \cdot \mathrm{h}^{-1}$, $\mathrm{g} \cdot \mathrm{mg}^{-1} \cdot \mathrm{h}^{-1}$, and $\mathrm{g} \cdot \mathrm{mg}^{-1} \cdot \mathrm{h}^{-0.5}$. C is the adsorption constant of the intra-particle diffusion model.

\subsection{Adsorption Thermodynamics}

Thermodynamic analysis of adsorption can describe the driving forces and directions of the adsorption process [41]. Through the study of biochar adsorption pollutants at different temperatures, the change in thermodynamic parameters in the adsorption process was calculated, and the thermodynamic formulas were used to calculate the $\Delta G, \Delta H$, and $\Delta S$. Its thermodynamic formula is as follows,

$$
\begin{gathered}
\Delta G=-R T \ln k_{d} \\
\Delta G=\Delta H-T \Delta S
\end{gathered}
$$

where $\Delta G$ is the change in Gibbs free energy, $\mathrm{kJ} \cdot \mathrm{mol}^{-1} ; \Delta H$ is the enthalpy change, $\mathrm{J} \cdot \mathrm{mol}^{-1}$; $\Delta S$ is the entropy change, $\mathrm{kJ} \cdot \mathrm{mol}^{-1} \cdot \mathrm{K}^{-1} ; R\left(8.314 \times 10^{-3} \mathrm{~kJ} \cdot \mathrm{mol}^{-1} \cdot \mathrm{K}^{-1}\right)$ is the ideal gas constant, $T$ is the absolute thermodynamic temperature, $K ; k_{d}$ is the adsorption constant, and it comes from $q_{e} / C_{e} . \Delta H$ and $\Delta S$ are derived from the slope and intercept by mapping $T$ by $\Delta G$. 


\section{Results and Discussion \\ 3.1. Materials Characterization \\ 3.1.1. Scanning Electron Microscopy (SEM) Analysis}

The surface morphology and structure of $B C, H B C$, and nZVI-HBC were observed by SEM images (Figure 1). Among them, BC has a rich porous structure and uneven surface, with disordered pairs of pore structures and varying sizes. The pore structure of $\mathrm{HBC}$ is relatively regular and there are few impurities in the pores, which provide a lot of space for the attachment of nanometer iron. nZVI-HBC shows that the nanosized zero-valent iron particles are amorphous, and the surface is relatively rough. Due to magnetic influence, some particles are agglomerated together in a chain shape [42]. The results show that the nano-zero iron can adhere to the surface of biochar and effectively prevent the aggregation of nanoparticles.
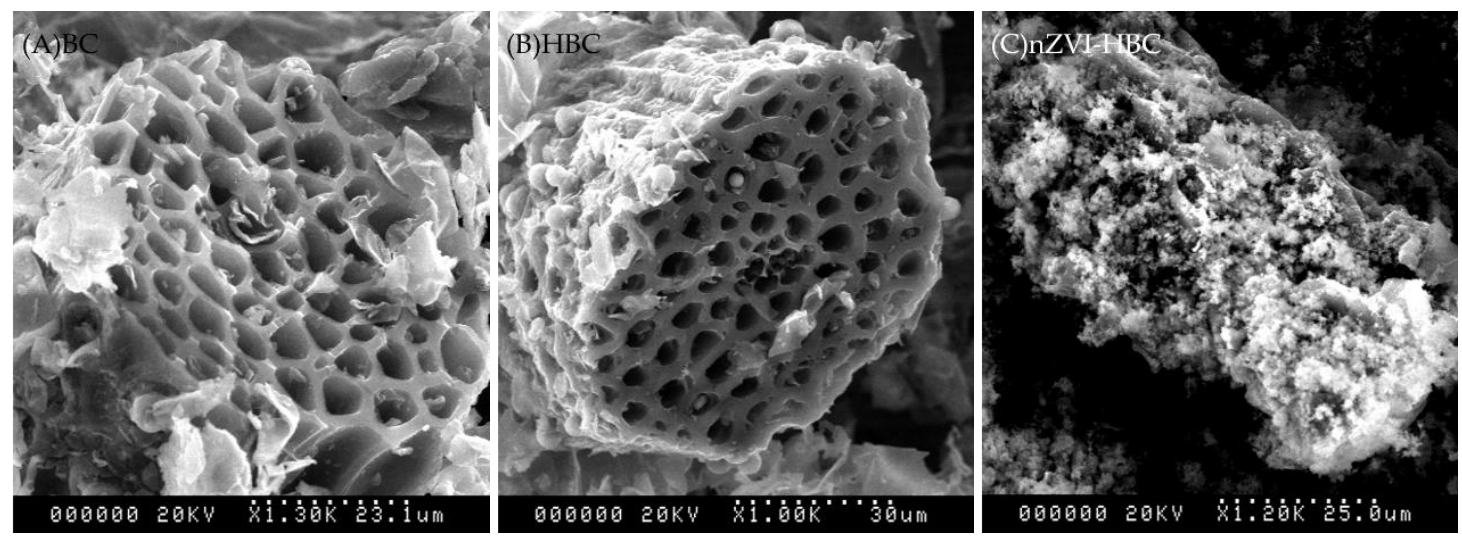

Figure 1. SEM images of biochar. (A) BC, (B) HBC, and (C) nZVI-HBC.

\subsubsection{X-ray Diffraction (XRD) Analysis}

XRD was performed on $B C, H B C$, and nZVI-HBC, and the results are shown in Figure 2. The XRD pattern of $B C$ shows that it has sharp peaks and a crystal structure. The peak body is mainly due to the presence of $\mathrm{SiO}_{2}$ and $\mathrm{CaCO}_{3}$. The characteristic peak about $2 \theta=25^{\circ}$ of $\mathrm{HBC}$ is the characteristic diffraction peak of coconut shell carbonization 002. The characteristic peak at $2 \theta=45^{\circ}$ is the characteristic diffraction peak of coconut shell carbonization 100. For nZVI-HBC, it is evident that the XRD pattern shows the characteristic peak of zero-valent iron corresponding to 110 plane diffraction volume center cubes when the diffraction peak $2 \theta=44.8^{\circ}$, indicating that nano-zero-iron successfully loaded on HBC by the liquid-phase reduction method [43]. Its peak shape shows a certain diffusion phenomenon, indicating that the nanoparticles are in an amorphous state. In addition, the characteristic peak of $\mathrm{Fe}_{3} \mathrm{O}_{4}$ corresponds to $2 \theta=35.5^{\circ}$, meaning that a small part of surface nano-zero iron particles is oxidized to trivalent iron $[27,44]$. Surface oxidation produced by $\mathrm{Fe}_{3} \mathrm{O}_{4}$ largely prevents internal nZVI from contacting the air.

\subsubsection{Fourier-Transform Infrared Spectroscopy (FTIR) Analysis}

In this study, the infrared spectrum of biochar at $4000-400 \mathrm{~cm}^{-1}$ was measured to analyze its surface functional groups. The comparison of the infrared spectra of BC, HBC, and nZVI-HBC biochar is shown in Figure 3. The FTIR spectra of BC and HBC are similar. The corresponding absorption peak at a wavelength about $3415 \mathrm{~cm}^{-1}$ is the vibration peak of $-\mathrm{OH}$, the corresponding absorption peak at about $2356 \mathrm{~cm}^{-1}$ is the vibration peak of $\mathrm{C} \equiv \mathrm{N}$, the corresponding absorption peak at about $1634 \mathrm{~cm}^{-1}$ is of the $\mathrm{C}=\mathrm{O}$ vibration peak, and the corresponding absorption peak at about $1067 \mathrm{~cm}^{-1}$ is the $-\mathrm{OH}$ vibration peak [45-47]. This may speculate that the surfaces of BC and HBC may contain amino and hydroxyl clumps. In the FTIR spectrum of nZVI-HBC, in addition to the absorption peaks that appear between the BC and $\mathrm{HBC}$ above, the wavelength of about $662 \mathrm{~cm}^{-1}$ 
corresponds to the absorption peaks of the Fe-O telescopic vibration [48,49], indicating the synthesis of nZVI, which is consistent with the previous XRD conclusions.

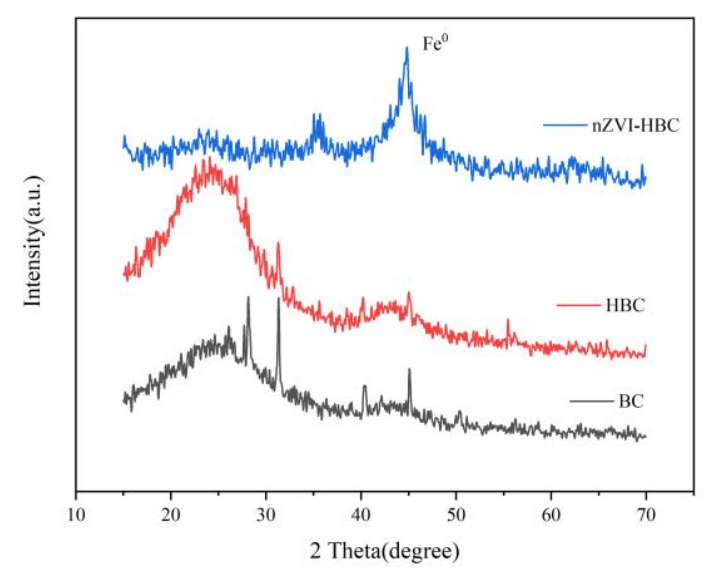

Figure 2. X-ray diffraction patterns of biochar.

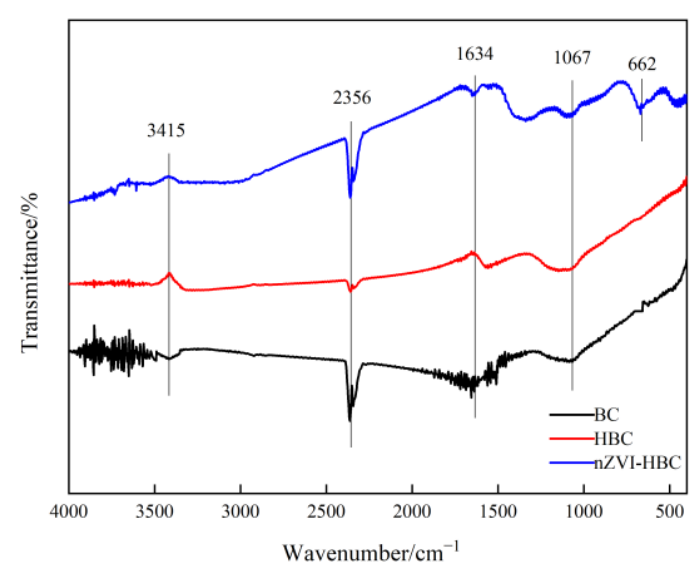

Figure 3. Fourier-transform infrared spectroscopy of biochar.

\subsubsection{X-ray Photoelectron Spectroscopy (XPS) Analysis}

XPS was used to characterize the surface element morphology of nZVI-HBC. Figure 4 shows the XPS spectrum of nZVI-HBC, the spectrum of iron, and its relevant results. The spectrum of Fe $2 \mathrm{p}$ can determine the valence of iron elements on the surface of the material. As shown in the figure, the absorption peak at $705.97 \mathrm{eV}$ is that of zero-valent iron, which proves that zero-valent iron successfully loaded on biochar by the liquid-phase reduction method [50]. The absorption peaks at $709.51 \mathrm{eV}$ and $723.11 \mathrm{eV}$ are characteristic peaks of $\mathrm{Fe}^{2+}$, and those at $711.73 \mathrm{eV}$ and $725.33 \mathrm{eV}$ are characteristic peaks of $\mathrm{Fe}^{3+}$ [51]. Among them, the appearance of $\mathrm{Fe}^{2+}$ and $\mathrm{Fe}^{3+}$ absorption peaks are caused by the oxidation of the $\mathrm{Fe}^{0}$ surface in contact with air to form different iron oxides. 


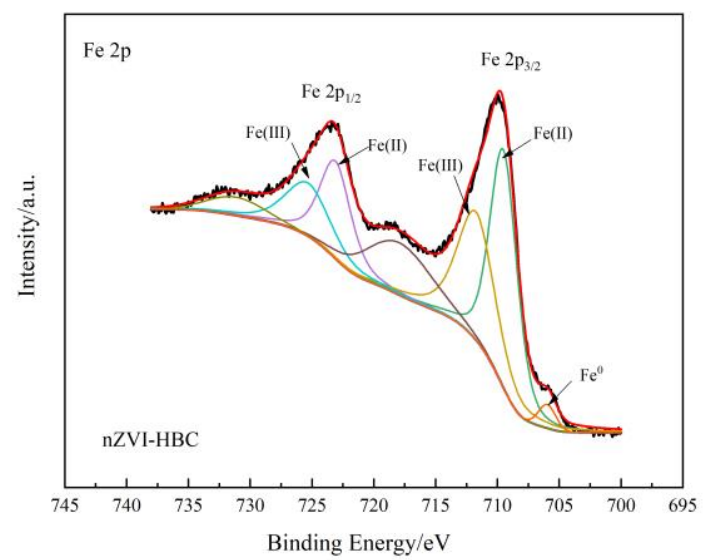

Figure 4. XPS diagram of nZVI-HBC.

\subsection{Batch Adsorption Experiment}

\subsubsection{Influence of Biochar Addition Amount on OTC Removal Effect}

Figure 5 shows the effect of different biochar additions on the adsorption rate of OTC. Among them, the adsorption rate of OTC increases linearly with the increase in BC addition, and when the amount of $\mathrm{BC}$ addition is $20 \mathrm{mg}$, the adsorption rate of OTC is $79.925 \%$. The removal rate of OTC increases rapidly when HBC addition is $2-10 \mathrm{mg}$, while the removal rate tends to be flat after $10 \mathrm{mg}$. For nZVI-HBC, when the dosage is $6 \mathrm{mg}$, the removal rate reaches $91.192 \%$, and then the removal rate is not more than $7.49 \%$. With the rise in the amount of $\mathrm{nZVI-HBC}$ added, the active sites involved in the reaction in the solution also increase, resulting in an increase in the removal rate. However, with the increasing amount of biochar added, there are too many available adsorption sites. Still, the concentration of antibiotics in the solution is limited, so the removal rate of antibiotics does not change [52]. To sum up, to obtain the best adsorption effect and economic benefit, the addition level of $6 \mathrm{mg}$ was selected for subsequent experiments.

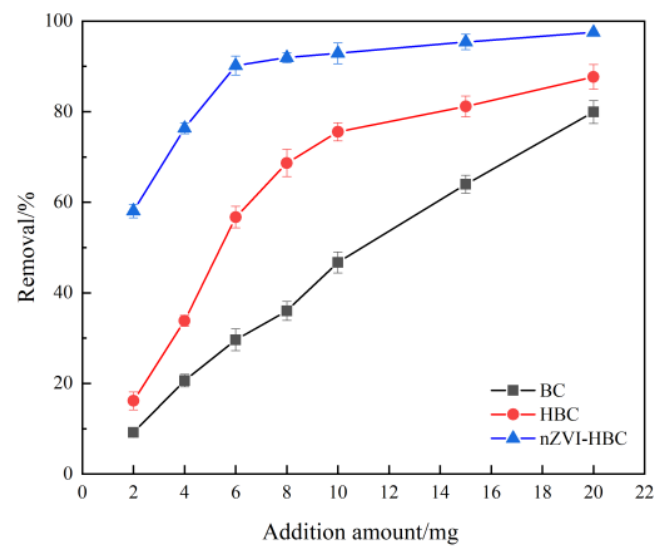

Figure 5. The effect of biochar addition on OTC removal rate.

\subsubsection{Influence of Initial $\mathrm{pH}$ on OTC Removal Effect}

Figure 6 shows the effect of biochar on the adsorption rate of OTC at different $\mathrm{pH}$ values. When $\mathrm{pH}=3, \mathrm{BC}$ and $\mathrm{HBC}$ have the highest adsorption rate, and $\mathrm{OTC}^{+}$is the main form of OTC in the solution, which has electrostatic repulsion with positively charged biochar. At this time, the adsorption rates of $\mathrm{BC}$ and $\mathrm{HBC}$ are highest, indicating that, in addition to electrostatic interaction, there are mechanisms such as $\pi-\pi$ EDA interaction during the adsorption of $\mathrm{BC}$ and $\mathrm{HBC}$. With the increase in $\mathrm{pH}$, the adsorption rate of the OTC decreases gradually and reaches the lowest value at $\mathrm{pH}=11$. 


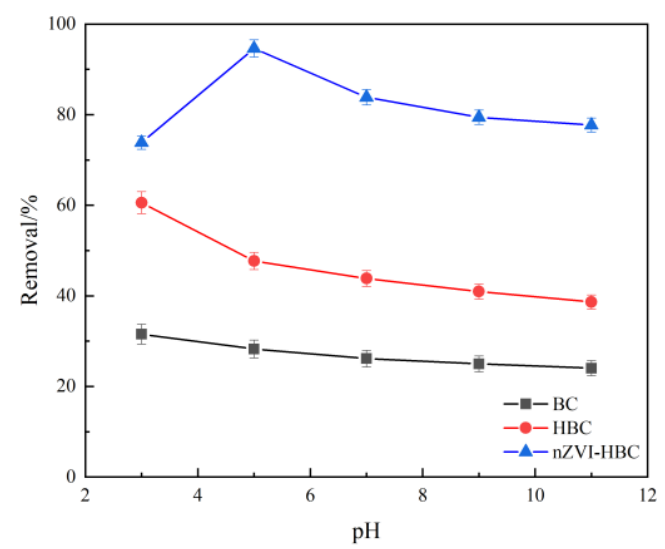

Figure 6. The effect of biochar addition on OTC removal rate.

For nZVI-HBC, the removal rate of OTC is lowest when $\mathrm{pH}=3$, because under acidic conditions, iron begins to rapidly corrode to produce bivalent iron, which leads to the generation of large numbers of hydrogen and hydrogen free radicals. Moreover, reducing hydrogen may directly reduce and degrade OTC, resulting in the lowest OTC removal rate. When $\mathrm{pH}=5$, OTC has the highest removal rate, which is because the particles are positively charged, and the electrostatic repulsion between particles makes the particles more easily dispersed, thus providing more active sites and causing the adsorption of OTC [53].

In addition, the concentration of the OTC decreases slightly the alkaline environment. This is due to the high $\mathrm{pH}$ value, the OTC being a negative charge state, and the nZVI-HBC surface also being a negative charge state, resulting in static rejection between the material and OTC, and iron corrosion will form an oxidation layer on the surface of the material. The active sites on the material surface are reduced, leading to a gradual decrease in the removal rate.

\subsubsection{Influence of Cation on OTC Removal Effect}

The effect of cation type on the adsorbent in aqueous solution is closely related to its valence, and the effect of common cations on biochar adsorption OTC was selected [54], such as $\mathrm{Na}^{+}, \mathrm{K}^{+}, \mathrm{Mg}^{2+}$, and $\mathrm{Ca}^{2+}$. The concentration of cations is $0.1 \mathrm{~mol} \cdot \mathrm{L}^{-1}$, and the OTC concentration is $20 \mathrm{mg} \cdot \mathrm{L}^{-1}$, with the experimental volume of $50 \mathrm{~mL}$. The inhibition of the adsorption rate of the four cations to OTC as shown in Figure 7 is as follows: $\mathrm{Ca}^{2+}>\mathrm{Mg}^{2+}$ $>\mathrm{K}^{+}>\mathrm{Na}^{+}$. Cations with relatively high valence state have a stronger inhibition on OTC removal efficiency. At the same time, it can also be seen that cations with larger ionic radius in the same valence state have stronger competitiveness, occupying more active sites on the surface of biochar, the OTC removal inhibition is more obvious.. Among them, the inhibition of cations to BC and HBC to remove OTC is not apparent. For nZVI-HBC, $\mathrm{Mg}^{2+}$ and $\mathrm{Ca}^{2+}$ may react with them to produce an iron oxide on the surface of the material to more inhibit the removal of pollutants. 


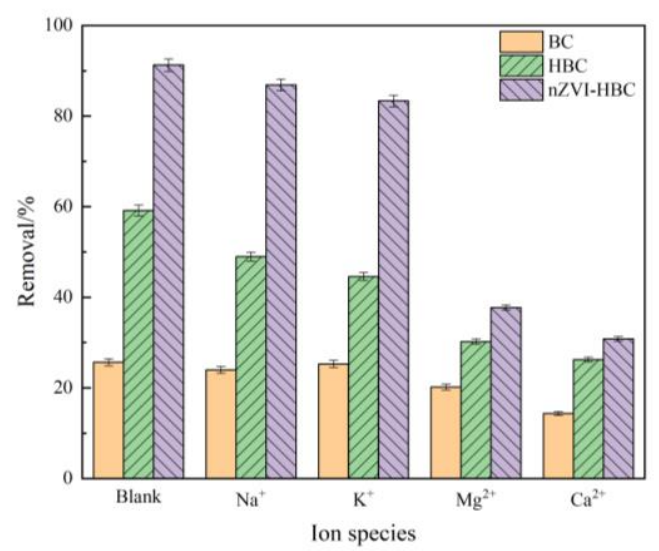

Figure 7. The effect of cations on OTC removal rate.

\subsubsection{Influence of Anions on OTC Removal Effect}

The anions of $\mathrm{NO}_{3}{ }^{-}, \mathrm{CO}_{3}{ }^{2-}$, and $\mathrm{HCO}_{3}{ }^{-}$were selected, and their ionic concentration was $0.1 \mathrm{~mol} \cdot \mathrm{L}^{-1}$, experimented at an OTC concentration of $20 \mathrm{mg} \cdot \mathrm{L}^{-1}$, and a volume of $50 \mathrm{~mL}$. As shown in Figure 8, the three anions have different degrees of inhibition effect on OTC adsorption efficiency. Among them, for $\mathrm{BC}$ and $\mathrm{HBC}$, the inhibition is $\mathrm{CO}_{3}{ }^{2-}$ > $\mathrm{HCO}_{3}{ }^{-}>\mathrm{NO}_{3}{ }^{-}$, because the solution after hydrolysis of acid root ions is alkaline. At the same time, OTC molecules are in an anion state under alkaline conditions, thus inhibiting OTC removal.

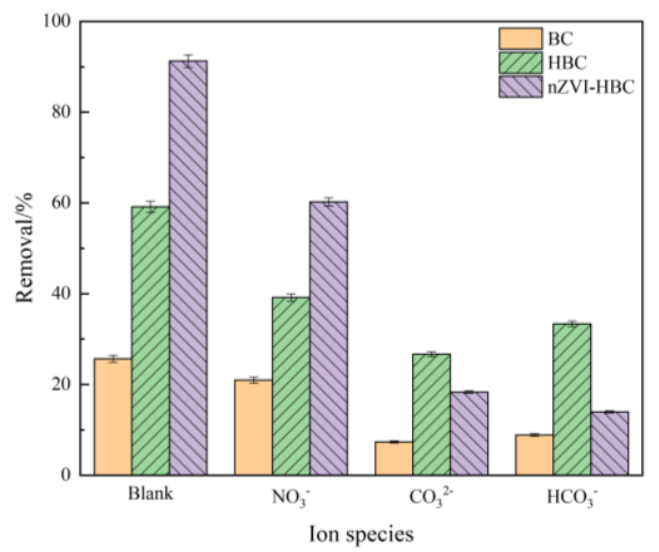

Figure 8. The effect of anions on OTC removal rate.

For nZVI-HBC, the inhibition is $\mathrm{HCO}^{3-}>\mathrm{CO}_{3}{ }^{2-}>\mathrm{NO}_{3}{ }^{-}$, because have a higher redox potential of $\mathrm{NO}_{3}{ }^{-}$, nano-zero iron particles were given priority to reduce $\mathrm{NO}_{3}{ }^{-}$, and the formation of iron oxides leads to passivation on the surface of nZVI-HBC to reduce reaction activity, and reduces the reaction rate. $\mathrm{CO}_{3}{ }^{2-}$ will accelerate the corrosion of iron and promote the generation of bivalent iron. As the reaction proceeds, iron particles form sediments or complexes such as siderite, iron carbonate hydroxide, aragonite, or calcite and other passivation films, reducing the reactivity of zero-valent iron and reducing the removal of pollutants. $\mathrm{HCO}_{3}{ }^{-}$may react with zero-valent iron to produce $\mathrm{CO}_{3}{ }^{2-}$, resulting in an initial $\mathrm{pH}$ increase in the solution, inhibiting the removal of OTC. In addition, the presence of $\mathrm{HCO}_{3}{ }^{-}$may lead to the formation of $\mathrm{Fe}^{2+}$ after the corrosion of nZVI possibly reacting with $\mathrm{HCO}_{3}{ }^{-}$to produce ferrous carbonate $\left(\mathrm{FeCO}_{3}\right)$, which will inhibit the reactivity of metal materials. 


\subsubsection{Influence of Ion Concentration on OTC Removal Effect}

The research shows that electrolytes in the solution not only change the strength of the interaction between adsorbent and adsorbent in the solution due to electrostatic action, but also compete with the adsorption sites on adsorbent with antibiotics, thus affecting the adsorption removal efficiency. As shown in Figure 9, the introduction of $\mathrm{Na}^{+}$ions inhibits the biochar adsorption of OTC to varying degrees. Still, with the increase in the concentration of $\mathrm{Na}^{+}$ions, the removal rate does not change significantly. On the one hand, $\mathrm{Na}^{+}$ions in solution can lead to an electrostatic effect, which affects the adsorption capacity of biochar to OTC. On the other hand, because of the solution with high salt ion concentration, OTC molecules are not easy to release from the whole, resulting in poor solubility, thereby reducing adsorption capacity. It is also possible that $\mathrm{Na}^{+}$ions react with functional groups on the surface of biochar, or that it competes with the OTC molecules for the adsorption sites on the surface of biochar, thereby inhibiting the adsorption of the OTC [55].

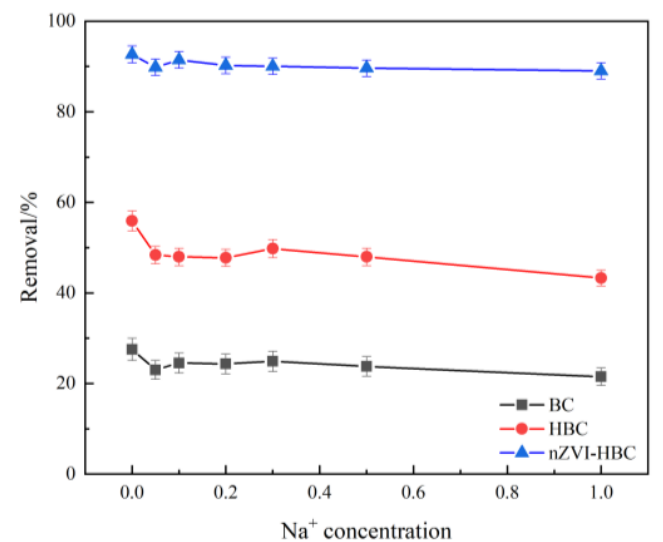

Figure 9. The effect of $\mathrm{Na}^{+}$concentration on OTC removal rate.

\subsubsection{Adsorption Isotherm Analysis}

The adsorption isotherm refers to the relationship between the equilibrium concentration $\left(C_{e}\right)$ of adsorption capacity $\left(q_{e}\right)$ when the adsorption reaches equilibrium under certain temperature conditions. Figure 10 shows the adsorption effects of biochar to different concentrations of OTC at ambient temperatures of $288.15 \mathrm{~K}, 298.15 \mathrm{~K}$, and $308.15 \mathrm{~K}$. The fitting data are shown in Table 1. In general, with the increase in temperature, the adsorption capacity of BC, HBC, and nZVI-HBC to OTC gradually increases, the initial concentration of OTC increases, and the adsorption of biochar also steadily increases. Among them, the adsorption of OTC by BC, HBC, and nZVI-HBC conforms to the Langmuir model. The linear correlation coefficients $\mathrm{R}^{2}$ are better than 0.9848 , which is much larger than the linear correlation coefficient of the Freundlich model $\left(R^{2}>0.8712\right)$. In the Temkin model, the linear correlation coefficients $\mathrm{R}^{2}$ are greater than 0.9845 .

In the Langmuir model, $q_{m}$ and $K_{L}$ increase with ambient temperature, indicating that the higher the temperature, the higher the adsorption site of $\mathrm{BC}, \mathrm{HBC}$, and nZVIHBC materials and OTC molecular adsorption, with good adsorption effect, and the adsorption process is heat absorption. In the Freundlich model, $n>1$ and increases with temperature, indicating that OTC is readily adsorbed to the biochar surface. As the ambient temperature increases, the value of $K_{F}$ increases, indicating that the adsorption capacity of the material also increases. In the Temkin model, the " $\mathrm{b}$ " value decreases with the temperature, implying that the adsorption affinity between the adsorption active sites and OTC molecules is also increasing. 

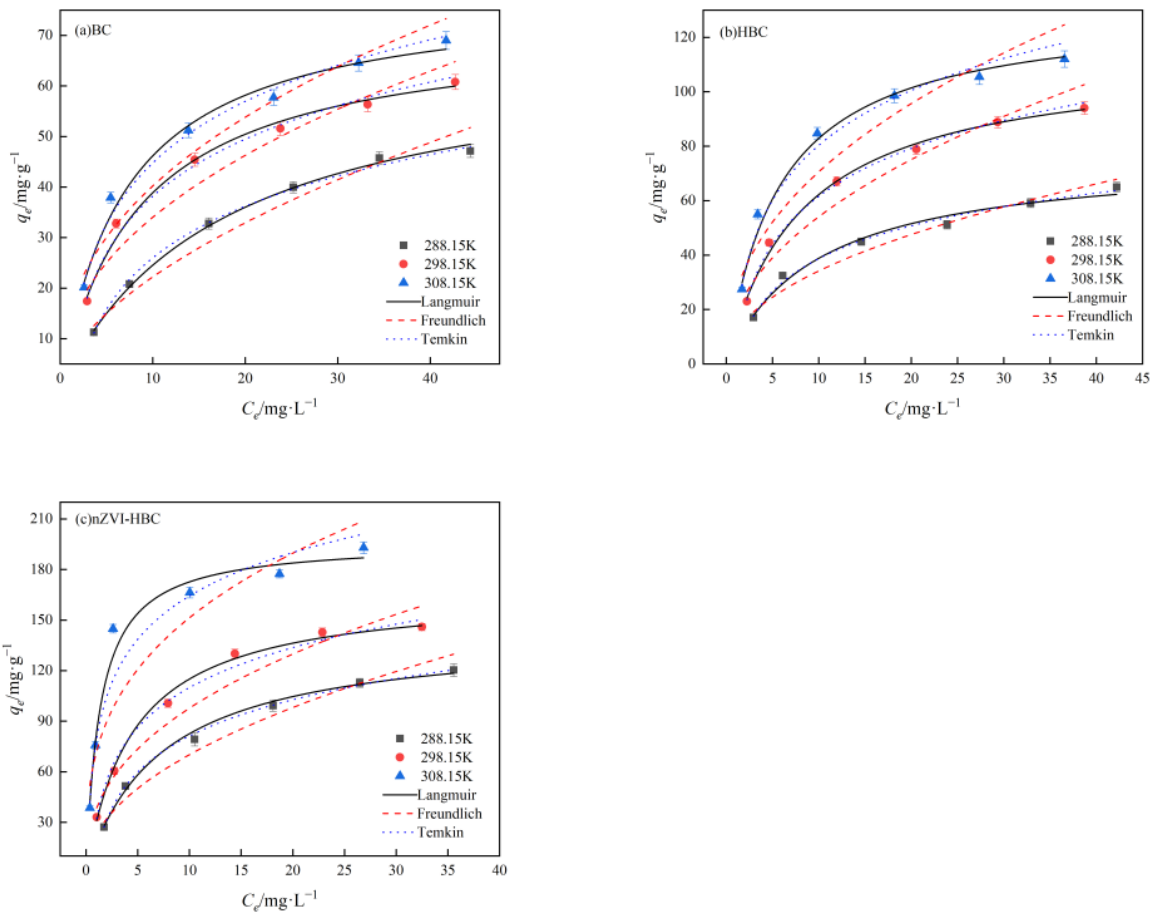

Figure 10. Adsorption isotherms of OTC with (a) BC, (b) HBC, and (c) nZVI-HBC.

Table 1. Adsorption isothermal equation fitting parameters of OTC adsorption of BC, HBC, and nZVI-HBC.

\begin{tabular}{|c|c|c|c|c|c|c|c|c|c|c|}
\hline & \multirow{2}{*}{$T / K$} & \multicolumn{3}{|c|}{ Langmuir } & \multicolumn{3}{|c|}{ Freundlich } & \multicolumn{3}{|c|}{ Temkin } \\
\hline & & $q_{m} / \mathrm{mg} \cdot \mathrm{g}^{-1}$ & $K_{L} / \mathrm{L} \cdot \mathrm{mg}^{-1}$ & $R^{2}$ & $n$ & $K_{F} / \mathrm{mg} \cdot \mathrm{L}^{-1}$ & $R^{2}$ & $B$ & $K_{T} / \mathbf{L} \cdot \mathbf{m g}^{-1}$ & $R^{2}$ \\
\hline \multirow{4}{*}{$\mathrm{BC}$} & 288.15 & 67.6953 & 0.0568 & 0.9977 & 1.7603 & 6.0044 & 0.9681 & 0.1623 & 0.5816 & 0.9974 \\
\hline & 298.15 & 71.9277 & 0.1174 & 0.9892 & 2.2525 & 12.2370 & 0.9405 & 0.1520 & 1.0383 & 0.9905 \\
\hline & 308.15 & 78.6155 & 0.1421 & 0.9868 & 2.3783 & 15.2701 & 0.9416 & 0.1457 & 1.2748 & 0.9877 \\
\hline & 288.15 & 76.7222 & 0.1025 & 0.9858 & 2.0997 & 11.4201 & 0.9555 & 0.1379 & 0.9300 & 0.9924 \\
\hline \multirow{3}{*}{$\mathrm{HBC}$} & 298.15 & 113.3720 & 0.1217 & 0.9927 & 2.1155 & 18.2221 & 0.9465 & 0.0975 & 1.1297 & 0.9967 \\
\hline & 308.15 & 130.6579 & 0.1735 & 0.9855 & 2.1560 & 25.7669 & 0.9131 & 0.0882 & 1.5901 & 0.9845 \\
\hline & 288.15 & 142.7134 & 0.1372 & 0.9968 & 2.0598 & 22.9187 & 0.9726 & 0.0773 & 1.3756 & 0.9992 \\
\hline \multirow[t]{2}{*}{ nZVI-HBC } & 298.15 & 167.2904 & 0.2199 & 0.9957 & 2.4370 & 37.9853 & 0.9582 & 0.0723 & 2.4721 & 0.9979 \\
\hline & 308.15 & 196.6985 & 0.7208 & 0.9848 & 3.0709 & 71.5141 & 0.8712 & 0.6895 & 8.3281 & 0.9956 \\
\hline
\end{tabular}

According to the simulation results, when the ambient temperature is $308.15 \mathrm{~K}$,

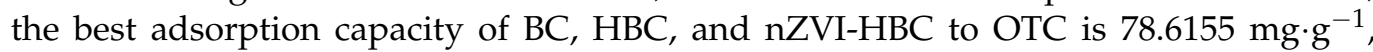
$130.6579 \mathrm{mg} \cdot \mathrm{g}^{-1}$, and $196.6985 \mathrm{mg} \cdot \mathrm{g}^{-1}$.

\subsubsection{Adsorption Thermodynamics}

To reveal the adsorption behavior of $\mathrm{BC}, \mathrm{HBC}$, and nZVI-HBC, the thermodynamics were calculated. The thermodynamic parameters of $\mathrm{BC}, \mathrm{HBC}$, and nZVI-HBC biochar for OTC in solution are shown in the table.

As shown in Table 2, the ambient temperature is $288.15 \mathrm{~K}, 298.15 \mathrm{~K}$, and $308.15 \mathrm{~K}$, and $\mathrm{BC}, \mathrm{HBC}$, and nZVI-HBC all have negative values for OTC adsorption of $\triangle \mathrm{G}$, indicating that the adsorption reaction is spontaneous and consistent with previous research results. $|\Delta \mathrm{G}|$ increases with the ambient temperature, suggesting that with the rise in ambient temperature, the degree of the spontaneity of the reaction increases. The value of $\Delta \mathrm{H}$ is positive, meaning that the adsorption process is endothermic, and the higher the temperature, the better the degree of adsorption. The values of $\Delta S$ are positive, indicating that the reaction is an entropy increase process, the adsorption reversibility is poor, and the randomness of the solid-liquid interface increases with the temperature [56]. 
Table 2. Thermodynamic parameters of OTC adsorption of BC, HBC, and nZVI-HBC.

\begin{tabular}{ccccc}
\hline & $\boldsymbol{T} / \mathbf{K}$ & $\boldsymbol{\Delta} \mathbf{G} / \mathbf{K J} \cdot \mathbf{~ m o l}^{-\mathbf{1}}$ & $\boldsymbol{\Delta H} / \mathbf{K J} \cdot \mathbf{m o l}^{-\mathbf{1}}$ & $\Delta S / \mathbf{K J} \cdot \mathbf{m o l}^{-\mathbf{1} \cdot \mathbf{K}^{-\mathbf{1}}}$ \\
\hline \multirow{2}{*}{ BC } & 288.15 & -7.8202 & & \\
& 298.15 & -9.8900 & 32.7392 & 0.1409 \\
& 308.15 & -10.7110 & & \\
HBC & 288.15 & -9.2327 & & 0.0929 \\
& 298.15 & -9.9790 & 17.6457 & \\
nZVI-HBC & 308.15 & -11.2227 & & 0.2469 \\
& 288.15 & -9.9326 & & \\
\hline
\end{tabular}

\subsubsection{Adsorption Kinetics}

Figure 11 shows the effect of adsorption time on the removal of OTC by BC, HBC, and nZVI-HBC. The results of the adsorption dynamics fit are shown in Table 3. As shown in the table, the correlation coefficients in the pseudo-first-order and pseudo-second-order dynamics model are above 0.9064 , the $\mathrm{BC}, \mathrm{HBC}$, and nZVI-HBC are more in line with the pseudo-second-order dynamics model, and the linear correlation coefficients $\mathrm{R}^{2}$ are 0.9760 , 0.9723 , and 0.9976 , respectively, which better describes the adsorption dynamics of OTC on adsorbents. In addition, the adsorption capacity $\left(q_{e}\right)$ of BC, HBC, and nZVI-HBC to OTC at equilibrium is closer to the theoretical value derived from the pseudo-second-order dynamics model.
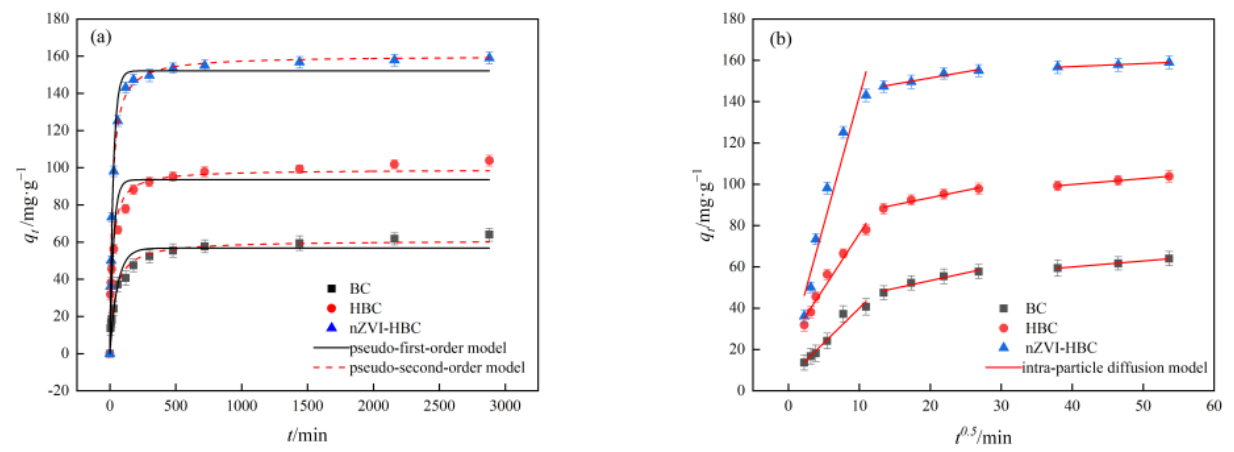

Figure 11. Adsorption kinetics curves of OTC adsorption of BC, HBC, and nZVI-HBC. (a) pseudofirst-order and pseudo-second-order dynamics model. (b) intra-particle diffusion model.

Table 3. Pseudo-first-order and pseudo-second-order dynamics model fitting parameters of OTC adsorption of BC, HBC, and nZVI-HBC.

\begin{tabular}{ccccccc}
\hline & \multicolumn{2}{c}{ Pseudo-First-Order Dynamics Model } & \multicolumn{2}{c}{ Pseudo-Second-Order Dynamics Model } \\
\cline { 2 - 7 } & $\boldsymbol{k}_{\mathbf{1}} / \mathbf{m i n}^{-\mathbf{1}}$ & $\boldsymbol{q}_{\boldsymbol{e}} / \mathbf{~} \mathbf{m g} \cdot \mathbf{g}^{-\mathbf{1}}$ & $\boldsymbol{R}^{\mathbf{2}}$ & $\boldsymbol{k}_{\mathbf{2}} / \mathbf{m i n}^{-\mathbf{1}}$ & $\boldsymbol{q}_{\boldsymbol{e}} / \mathbf{m g} \cdot \mathbf{g}^{-\mathbf{1}}$ & $\boldsymbol{R}^{\mathbf{2}}$ \\
\hline BC & 0.0174 & 56.7510 & 0.9248 & 0.0004 & 60.8867 & 0.9760 \\
HBC & 0.0361 & 93.5487 & 0.9064 & 0.0005 & 99.0229 & 0.9723 \\
nZVI-HBC & 0.0376 & 152.1172 & 0.9854 & 0.0003 & 160.2055 & 0.9976 \\
\hline
\end{tabular}

The results show that the adsorption of $\mathrm{BC}, \mathrm{HBC}$, and $\mathrm{nZVI-HBC}$ on OTC is mainly based on chemical adsorption. The adsorption can quickly achieve adsorption balance, which is related to the OTC molecular structure containing more aromatic ring structures. The three biochars can be reacted with OTC through the $\pi-\pi$ interaction [57].

To better explain the adsorption mechanism, it was further fitted by the intra-particle diffusion model, and the results show that OTC adsorption on biochar is divided into three stages. The fitting results are shown in Table 4 . The first stage is rapid film diffusion, and due to the presence of a large number of adsorption sites, the reaction takes place quickly. 
The second stage is the slow particle internal adsorption stage. Here, the adsorption site of the biochar surface is gradually saturated, and the adsorption rate gradually decreases. The third stage is the adsorption-desorption balance stage. Here, adsorption has reached a balance, the diffusion rate in the pore decreases, and the adsorption will not increase with time. The linear correlation coefficient $R^{2}$ of each part is also more than 0.9176 , and its intercept " $\mathrm{C}$ " gradually increases with time, indicating that the film diffusion has a more substantial effect.

Table 4. Intra-particle diffusion model fitting parameters of OTC adsorption of BC, HBC, and nZVI-HBC.

\begin{tabular}{|c|c|c|c|c|c|c|c|c|c|}
\hline & $\underset{\mathrm{Kmg} \cdot \mathrm{g}^{-1} \cdot \mathrm{min}^{-0.5}}{ }$ & $C_{1}$ & $R_{1}^{2}$ & $\frac{K_{\mathrm{i} 2}}{/ \mathrm{mg} \cdot \mathrm{g}^{-1} \cdot \min ^{-0.5}}$ & $C_{2}$ & $R_{2}{ }^{2}$ & $\stackrel{K_{\mathrm{i} 3}}{/ \mathrm{mg} \cdot \mathrm{g}^{-1} \cdot \min ^{-0.5}}$ & $C_{3}$ & $R_{3}^{2}$ \\
\hline BC & 3.3681 & 6.3466 & 0.9379 & 0.7462 & 38.4293 & 0.9281 & 0.2888 & 48.4239 & 0.9952 \\
\hline HBC & 5.2774 & 23.2910 & 0.9596 & 0.7041 & 79.4408 & 0.9543 & 0.2898 & 88.2895 & 0.9990 \\
\hline nZVI-HBC & 12.4327 & 18.3370 & 0.9176 & 0.5996 & 139.4657 & 0.9457 & 0.1444 & 151.2029 & 0.9952 \\
\hline
\end{tabular}

\subsection{Analysis of Degradation Products and Adsorption Mechanism}

\subsubsection{Degradation Products}

During the reaction of nZVI-HBC to remove OTC, the metabolites produced in the reaction process were detected and analyzed by mass spectrometry. Its degradation products were mainly determined by different mass ratios in mass spectrometry [58,59]. The highest peak in $\mathrm{m} / \mathrm{z} 461$ is the ion peak of OTC, which proves that the primary substance in the original solution is OTC.

With the addition of nZVI-HBC, the ion peak strength of OTC is reduced, meaning that the concentration of OTC decreases, as well as the emergence of ion peaks of other strengths, indicating that OTC degrades during removal and produces new substances. The degradation path and degradation product of OTC are inferred from mass spectrometry; the results shown in Figure 12.

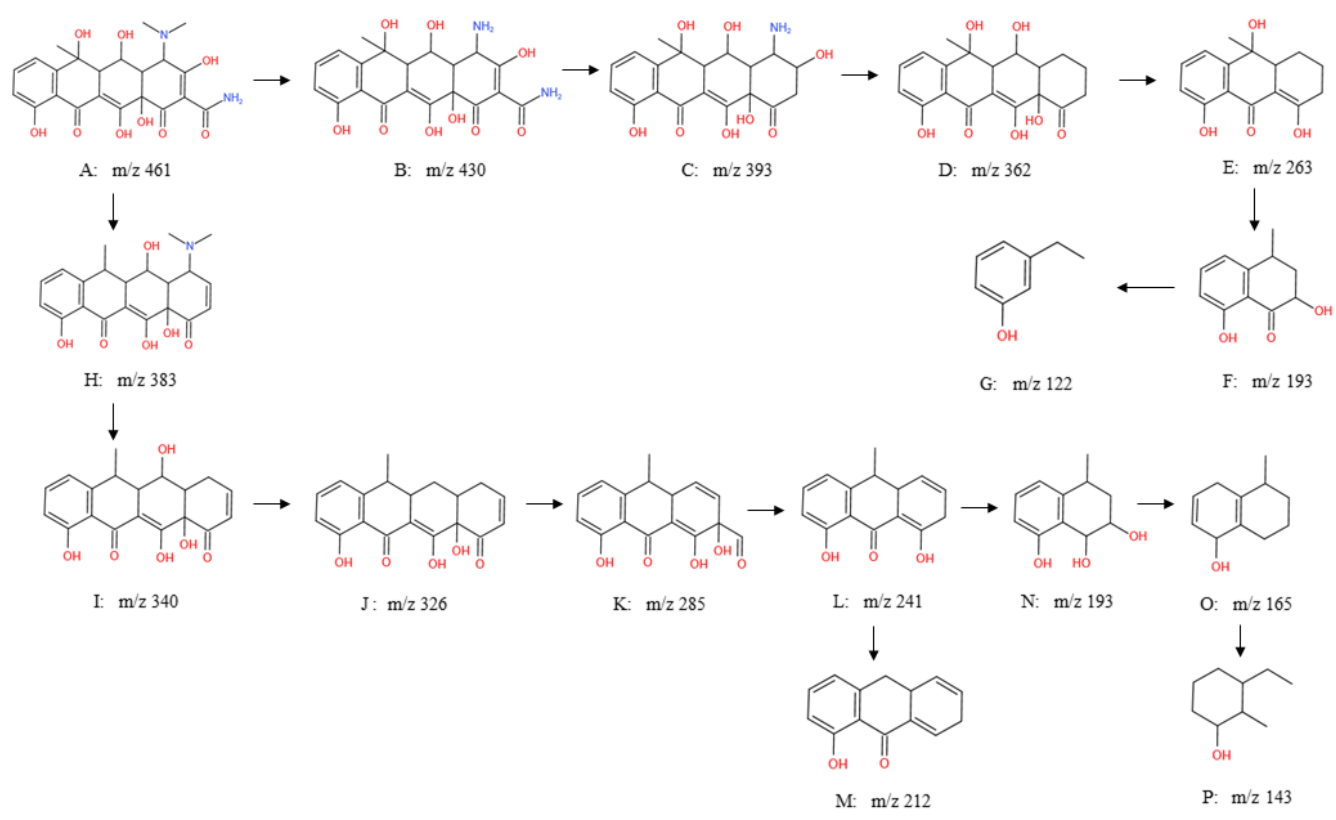

Figure 12. Degradation pathway of OTC.

As shown in Figure 12, there are two main degradation paths. One path is: the generation of " $\mathrm{B}$ " is due to the loss of two $\mathrm{N}$-methyl groups over the OTC. " $\mathrm{C}$ " is then formed by the removal of the amide group, based on which the absence of hydroxyl and amino groups is converted into " $\mathrm{D}$," and " $\mathrm{E}$ " is generated through ring-opening reactions, dihydroxylation reactions, and the removal of an acetyl group. The formation of " $\mathrm{F}$ " is 
due to the ring-opening reaction of "E," the removal of a propyl group, and the removal of carboxyl, with an hydroxyl group replacing an acetyl group. The absence of methyl, carboxyl, and aldehyde groups on " $\mathrm{F}$ " and the ring-opening reaction produce "G."

The second path is: the loss of methyl, carboxyl, and amide groups on " $\mathrm{A}$ " forms " $\mathrm{H}$," while removing methyl and amino groups on " $\mathrm{H}$ " generates " $\mathrm{I}$ " " $\mathrm{J}$ " is formed by the removal of an hydroxyl group from "I." " $\mathrm{J}$ " is then converted into " $\mathrm{K}$ " by a ring-opening reaction, with the reduction of ethyl, addition reaction, and demethylation. The removal of the aldehyde group and hydroxyl group on " $\mathrm{K}$ " produces " $\mathrm{L}$," in which " $\mathrm{L}$ " can form " $\mathrm{M}$ " through demethylation and the removal of the hydroxyl group. " $\mathrm{L}$ " can also be further developed by ring-opening reactions, the removal of propyl groups, and hydroxyl substitution of acetyl groups to form " $\mathrm{N}$ ". The formation of " $\mathrm{O}$ " is due to the removal of hydroxyl groups from "N." "P" is formed on "O" by demethylation, ring-opening, and elimination reactions.

\subsubsection{Mechanism Analysis}

By LC-MS analyses, the removal of OTC by material nZVI-HBC involves the following aspects:

(1) nZVI-HBC, because of its biochar adsorption properties and adsorption of OTC to the surface of the material, enhances the contact between pollutants and biochar;

(2) Part of the OTC is adsorbed and fixed to the surface by nZVI-HBC, and with the zero-valent iron reaction, partial degradation occurs;

(3) The main degradation reactions are oxidation reaction, ring-opening reaction, and the removal of functional groups;

(4) Some of the $\mathrm{Fe}^{2+}$ and $\mathrm{Fe}^{3+}$ products generated by the zero-valent iron in the air also adsorb a certain amount of OTC.

In summary, nZVI-HBC to OTC removal mainly includes adsorption and degradation.

\section{Conclusions}

(1) In this paper, the coconut shell was burned, and then the hydrochloric acid impregnation method was used, and the liquid-phase reduction method successfully prepared nZVI-HBC, and a series of characterization analyses was carried out to prove that nZVI was successfully loaded on HBC. In addition, nZVI can be well dispersed on the surface of $\mathrm{HBC}$, reducing the agglomeration of zero-valent iron.

(2) BC, HBC, and nZVI-HBC had specific removal effects on OTC, of which the removal effects were nZVI-HBC $>$ HBC $>$ BC. The adsorption capacity of nZVI-HBC to OTC was up to $196.70 \mathrm{mg} \cdot \mathrm{g}^{-1}$. The experiment showed that increasing the amount of biochar added was beneficial to OTC removal, and it was more beneficial to OTC removal under acidic conditions. It was shown that nZVI-HBC was a material with good adsorption performance and potential utilization value.

(3) The removal of OTC by nZVI-HBC included both adsorption and degradation. nZVI played an essential role in the removal of OTC. The degradation products and degradation path of OTC were inferred by LC-MS. Through the above experimental analysis, OTC was adsorbed on the material surface by nZVI-HBC, because of nZVI reduction of the surface adsorption of pollutants degradation removal.

Author Contributions: Conceptualization, Q.L. and S.Z.; Data curation, Q.L. and S.Z.; Investigation, S.Z. and Y.W.; Methodology, Q.L. and S.Z.; Resources, Q.L.; Supervision, Q.L.; Writing-original draft, Q.L. and S.Z.; Writing-review \& editing, Q.L., S.Z. and Y.W. All authors have read and agreed to the published version of the manuscript.

Funding: This research was funded by Second Tibetan Plateau Scientific Expedition and Research Program (No. 2019QZKK1003); Key Research and Development Plan of Shaanxi Province (No. 2020SF-400); Scientific Research Foundation of the Water Conservancy Department of Shaanxi Province (No. 2020slkj-13), and the Shaanxi Thousand Talent Program for Young Out-standing Scientists (No.334041900007). 
Institutional Review Board Statement: Not applicable.

Informed Consent Statement: Not applicable.

Data Availability Statement: The study did not report any data.

Acknowledgments: The authors gratefully thank the Second Tibetan Plateau Scientific Expedition and Research Program (No. 2019QZKK1003); Key Research and Development Plan of Shaanxi Province (No. 2020SF-400); Scientific Research Foundation of the Water Conservancy Department of Shaanxi Province (No. 2020slkj-13), and the Shaanxi Thousand Talent Program for Young Outstanding Scientists (No.334041900007).

Conflicts of Interest: The authors declare no conflict of interest.

\section{References}

1. World Health Organization. WHO releases the 2019 AWaRe Classification of Antibiotics. In Medical Chronicle; World Health Organization: New York, NY, USA, 2019; Volume 2019.

2. Liang, X.; Chen, B.; Nie, X.; Shi, Z.; Huang, X.; Li, X. The distribution and partitioning of common antibiotics in water and sediment of the Pearl River Estuary, South China. Chemosphere 2013, 92, 1410-1416. [CrossRef] [PubMed]

3. Biao, Z.; Shang, Q.; Xiangyu, G.; Kaidi, J.; Minhui, J.; Fei, L. Distribution of Antibiotic Resistance Genes in Karst River and Its Ecological Risk. Water Res. 2021, 203, 117507.

4. Fernández-Calviño, D.; Bermúdez-Couso, A.; Arias-Estévez, M.; Nóvoa-Muñoz, J.C.; Fernández-Sanjurjo, M.J.; ÁlvarezRodríguez, E.; Núñez-Delgado, A. Kinetics of tetracycline, oxytetracycline, and chlortetracycline adsorption and desorption on two acid soils. Environ. Sci. Pollut. Res. 2015, 22, 425-433. [CrossRef] [PubMed]

5. Mercan, Y.U.; Volkan, K.; Mikail, K.; Filiz, T.; Atalay, U.B. Adverse effects of oxytetracycline and enrofloxacin on the fertility of Saanen bucks. Trop. Anim. Health Prod. 2021, 53, 466.

6. Kubra, U.; Senem, Y.G.; Emine, C.; Fatih, I.; Gamze, V. Degradation of oxytetracycline in aqueous solution by heat-activated peroxydisulfate and peroxymonosulfate oxidation. Environ. Sci. Pollut. Res. Int. 2021, 1-14. [CrossRef]

7. Watkinson, A.J.; Murby, E.J.; Kolpin, D.W.; Costanzo, S.D. The occurrence of antibiotics in an urban watershed: From wastewater to drinking water. Sci. Total Environ. 2009, 407, 2711-2723. [CrossRef] [PubMed]

8. Rita, A.A.; Inês, D.; Isabel, H. Zebrafish and water microbiome recovery after oxytetracycline exposure. Environ. Pollut. 2020, $272,116371$.

9. Zou, S.; Xu, W.; Zhang, R.; Tang, J.; Chen, Y.; Zhang, G. Occurrence and distribution of antibiotics in coastal water of the Bohai Bay, China: Impacts of river discharge and aquaculture activities. Environ. Pollut. 2011, 159, 2913-2920. [CrossRef]

10. Adriano, W.S.; Veredas, V.; Santana, C.C.; Gonçalves, L.R.B. Adsorption of amoxicillin on chitosan beads: Kinetics, equilibrium and validation of finite bath models. Biochem. Eng. J. 2005, 27, 132-137. [CrossRef]

11. Zha, S.x.; Zhou, Y.; Jin, X.; Chen, Z. The removal of amoxicillin from wastewater using organobentonite. J. Environ. Manag. 2013, 129, 569-576. [CrossRef]

12. Venzke, C.D.; Giacobbo, A.; Ferreira, J.Z.; Bernardes, A.M.; Rodrigues, M.A.S. Increasing water recovery rate of membrane hybrid process on the petrochemical wastewater treatment. Process. Saf. Environ. Prot. 2018, 117, 152-158. [CrossRef]

13. Liang, D.H.; Hu, Y. Simultaneous sulfamethoxazole biodegradation and nitrogen conversion by Achromobacter sp. JL9 using with different carbon and nitrogen sources. Bioresour. Technol. 2019, 293, 122061. [CrossRef]

14. Yang, G.-H.; Bao, D.-D.; Zhang, D.-Q.; Wang, C.; Qu, L.-L.; Li, H.-T. Removal of Antibiotics From Water with an All-Carbon 3D Nanofiltration Membrane. Nanoscale Res. Lett. 2018, 13, 146. [CrossRef] [PubMed]

15. Pelalak, R.; Alizadeh, R.; Ghareshabani, E.; Heidari, Z. Degradation of sulfonamide antibiotics using ozone-based advanced oxidation process: Experimental, modeling, transformation mechanism and DFT study. Sci. Total Environ. 2020, 734, 139446. [CrossRef]

16. Yun, Z.; Sheng, F.; Xuemei, D.; Wei, Z.; Cong, S.; Wei, W.; Zhenfei, J.; Wei, L. $\mathrm{MnO}_{2}$ /UIO-66 improves the catalysed degradation of oxytetracycline under UV/ $\mathrm{H}_{2} \mathrm{O}_{2}$ /PMS system. J. Solid State Chem. 2021, 300, 122231.

17. Ahmed, E.H.; Kubra, U.A.; Hamza, E.H.; Cem, B.U.; Oum, K.K.; Abdelmalek, D.; Najia, K.; Abdallah, Z.; Eyup, D. Removal of Oxytetracycline by Graphene oxide and Boron-doped Reduced Graphene Oxide: A combined Density Function Theory, molecular dynamics simulation and experimental study. FlatChem 2021, 27, 100238.

18. Shujuan, L.; Xiaoshuang, S.; Mingyi, L.; Mengdan, Z.; Xiaohuan, D.; Xu, L.; Quan, F.; Rongbo, G. Accelerated adsorption of tetracyclines and microbes with FeOn $(\mathrm{OH}) \mathrm{m}$ modified oyster shell: Its application on biotransformation of oxytetracycline in anaerobic enrichment culture. Chem. Eng. J. 2021, 425, 130499.

19. Jia, M.; Wang, F.; Bian, Y.; Jin, X.; Song, Y.; Kengara, F.O.; Xu, R.; Jiang, X. Effects of pH and metal ions on oxytetracycline sorption to maize-straw-derived biochar. Bioresour. Technol. 2013, 136, 87-93. [CrossRef] [PubMed]

20. Jiawei, D.; Xiangfu, M.; Yuhu, Z.; Yunjie, H. Effects of modification and magnetization of rice straw derived biochar on adsorption of tetracycline from water. Bioresour. Technol. 2020, 311, 123455.

21. Imran-Shaukat, M.; Wahi, R.; Abdullah, S.M.A.A.; Ngaini, Z. Chemically Modified Coconut Shell Biochar for Removal of Heavy Metals from Aqueous Solution. Defect Diffus. Forum 2021, 411, 79-91. [CrossRef] 
22. Mostafa, N.A.; Farouk, S.M.; Abdelhamid, S.M.; Monazie, A.M. Optimisation and Characterisation of Bio-Adsorbent Based on Barley Straw and Coconut Shell. J. Environ. Eng. Sci. 2021, 40,1-10. [CrossRef]

23. Shen, Y.-S.; Wang, S.-L.; Tzou, Y.-M.; Yan, Y.-Y.; Kuan, W.-H. Removal of hexavalent Cr by coconut coir and derived chars-The effect of surface functionality. Bioresour. Technol. 2012, 104, 165-172. [CrossRef] [PubMed]

24. Liu, H.; Xu, F.; Xie, Y.; Wang, C.; Zhang, A.; Li, L.; Xu, H. Effect of modified coconut shell biochar on availability of heavy metals and biochemical characteristics of soil in multiple heavy metals contaminated soil. Sci. Total Environ. 2018, 645, 702-709. [CrossRef] [PubMed]

25. Pranoto; Martini, T.; Astuti, F.; Maharditya, W. Test the Effectiveness and Characterization of Quartz Sand/Coconut Shell Charcoal Composite as Adsorbent of Manganese Heavy Metal. IOP Conf. Ser. Mater. Sci. Eng. 2020, 858, 012041. [CrossRef]

26. Xi, L.; Ling, L. Recent advances in nanoscale zero-valent iron/oxidant system as a treatment for contaminated water and soil. $J$. Environ. Chem. Eng. 2021, 9, 106276.

27. Shao, Y.; Zhao, P.; Yue, Q.; Wu, Y.; Gao, B.; Kong, W. Preparation of wheat straw-supported Nanoscale Zero-Valent Iron and its removal performance on ciprofloxacin. Ecotoxicol. Environ. Saf. 2018, 158, 100-107. [CrossRef] [PubMed]

28. Hongyi, Z.; Mengyao, Y.; Yongkang, Z.; Ali, B.S.; Ning, H.; Mengyan, M. Sodium citrate and biochar synergistic improvement of nanoscale zero-valent iron composite for the removal of chromium (VI) in aqueous solutions. J. Environ. Sci. 2022, 115, 227-239.

29. Qian, L.; Zhongshan, C.; Huihui, W.; Hui, Y.; Tao, W.; Shuqin, W.; Baowei, H.; Xiangke, W. Removal of organic compounds by nanoscale zero-valent iron and its composites. Sci. Total Environ. 2021, 792, 148546.

30. Yadav, R.; Sharma, A.K.; Babu, J.N. Sorptive removal of arsenite [As(III)] and arsenate [As(V)] by fuller's earth immobilized nanoscale zero-valent iron nanoparticles (F-nZVI): Effect of Fe 0 loading on adsorption activity. J. Environ. Chem. Eng. 2016, 4, 681-694. [CrossRef]

31. Li, Z.; Wang, L.; Meng, J.; Liu, X.; Xu, J.; Wang, F.; Brookes, P. Zeolite-supported nanoscale zero-valent iron: New findings on simultaneous adsorption of $\mathrm{Cd}(\mathrm{II}), \mathrm{Pb}(\mathrm{II})$, and $\mathrm{As}(\mathrm{III})$ in aqueous solution and soil. J. Hazard. Mater. 2018, 344, 1-11. [CrossRef]

32. Yaru, L.; He-Ping, Z.; Lizhong, Z. Remediation of soil contaminated with organic compounds by nanoscale zero-valent iron: A review. Sci. Total Environ. 2021, 760, 143413.

33. Premarathna, K.S.D.; Rajapaksha, A.U.; Adassoriya, N.; Sarkar, B.; Sirimuthu, N.M.S.; Cooray, A.; Ok, Y.S.; Vithanage, M. Clay-biochar composites for sorptive removal of tetracycline antibiotic in aqueous media. J. Environ. Manag. 2019, 238, 315-322. [CrossRef] [PubMed]

34. Yaru, Y.; Chongyang, S.; Xiaoyuan, B.; Tiantian, L. Removal of hexavalent chromium from aqueous solution by fabricating novel heteroaggregates of montmorillonite microparticles with nanoscale zero-valent iron. Sci. Rep. 2020, 10, 12137.

35. Isiuku, B.O.; Okonkwo, P.C.; Emeagwara, C.D. Batch adsorption isotherm models applied in single and multicomponent adsorption systems-A review. J. Dispers. Sci. Technol. 2021, 42, 1879-1897. [CrossRef]

36. Syafiuddin, A.; Salmiati, S.; Jonbi, J.; Fulazzaky, M.A. Application of the kinetic and isotherm models for better understanding of the behaviors of silver nanoparticles adsorption onto different adsorbents. J. Environ. Manag. 2018, 218, 59-70. [CrossRef] [PubMed]

37. Min, P. Biochar Adsorption of Antibiotics and its Implications to Remediation of Contaminated Soil. Water Air Soil Pollut. 2020, $231,221$.

38. Jacek, P.; Katarzyna, I.; Tomasz, D. Analysis of Selected Methods Use for Calculation of the Coefficients of Adsorption Isotherms and Simplified Equations of Adsorption Dynamics with the Use of IZO Application. Materials 2021, 14, 4192.

39. Akhtarul, I.M.; Ahmed, C.M.; Islam, M.M.S.; Tamez, U.M. Langmuir Adsorption Kinetics in Liquid Media: Interface Reaction Model. ACS Omega 2021, 6, 14481-14492.

40. Bullen, J.C.; Saleesongsom, S.; Gallagher, K.; Weiss, D.J. A Revised Pseudo-Second-Order Kinetic Model for Adsorption, Sensitive to Changes in Adsorbate and Adsorbent Concentrations. Langmuir ACS J. Surf. Colloids 2021, 37, 3189-3201. [CrossRef] [PubMed]

41. Lima, E.C.; Gomes, A.A.; Tran, H.N. Comparison of the nonlinear and linear forms of the van't Hoff equation for calculation of adsorption thermodynamic parameters $\left(\Delta \mathrm{S}^{\circ}\right.$ and $\left.\Delta \mathrm{H}^{\circ}\right)$. J. Mol. Liq. 2020, 311, 113315. [CrossRef]

42. Weng, X.; Sun, Q.; Lin, S.; Chen, Z.; Megharaj, M.; Naidu, R. Enhancement of catalytic degradation of amoxicillin in aqueous solution using clay supported bimetallic Fe/Ni nanoparticles. Chemosphere 2014, 103, 80-85. [CrossRef] [PubMed]

43. Ma, J.-F.; Xing, J.-X.; Wang, K.; Yang, H.-Y.; Fei, B.-H.; Liu, X.-E. Inspired by efficient cellulose-dissolving system: Facile one-pot synthesis of biomass-based hydrothermal magnetic carbonaceous materials. Carbohydr. Polym. 2017, 164, 127-135. [CrossRef]

44. Yıldırım, G.M.; Bayrak, B. The synthesis of biochar-supported nano zero-valent iron composite and its adsorption performance in removal of malachite green. Biomass Convers. Biorefinery 2021, 1-13. [CrossRef]

45. Dubey, R.S.; Ganesan, V. Visible and near-infrared wavelength-selective dielectric reflectors for light management applications. Superlattices Microstruct. 2018, 122, 228-234. [CrossRef]

46. Hongcen, Y.; Shouwei, Z.; Ruya, C.; Xiaolong, D.; Zhipeng, L.; Xijin, X. Constructing the novel ultrafine amorphous iron oxyhydroxide/g-C3N4 nanosheets heterojunctions for highly improved photocatalytic performance. Sci. Rep. $2017,7,8686$.

47. Zheng, X.; Yu, N.; Wang, X.; Wang, Y.; Wang, L.; Li, X.; Hu, X. Adsorption Properties of Granular Activated Carbon-Supported Titanium Dioxide Particles for Dyes and Copper Ions. Sci. Rep. 2018, 8, 6463. [CrossRef]

48. Younes, A.A.; Abdulhady, Y.A.; Shahat, N.S.; El-Din El-Dars, F.M. Removal of cadmium ions from wastewaters using corn cobs supporting nano-zero valent iron. Sep. Sci. Technol. 2021, 56, 1-13. [CrossRef] 
49. Lyu, H.; Tang, J.; Cui, M.; Gao, B.; Shen, B. Biochar/iron (BC/Fe) composites for soil and groundwater remediation: Synthesis, applications, and mechanisms. Chemosphere 2020, 246, 125609. [CrossRef]

50. Xiao, J.; Gao, B.; Yue, Q.; Gao, Y.; Li, Q. Removal of trihalomethanes from reclaimed-water by original and modified nanoscale zero-valent iron: Characterization, kinetics and mechanism. Chem. Eng. J. 2015, 262, 1226-1236. [CrossRef]

51. Zhu, F.; Wu, Y.; Liang, Y.; Li, H.; Liang, W. Degradation mechanism of norfloxacin in water using persulfate activated by BC@nZVI/Ni. Chem. Eng. J. 2020, 389, 124276. [CrossRef]

52. Wang, H.; Yuan, X.; Wu, Y.; Huang, H.; Zeng, G.; Liu, Y.; Wang, X.; Lin, N.; Qi, Y. Adsorption characteristics and behaviors of graphene oxide for Zn(II) removal from aqueous solution. Appl. Surf. Sci. 2013, 279, 432-440. [CrossRef]

53. Yin, C.Y.; Aroua, M.K.; Daud, W.M.A.W. Review of modifications of activated carbon for enhancing contaminant uptakes from aqueous solutions. Sep. Purif. Technol. 2006, 52, 403-415. [CrossRef]

54. Gisi, S.D.; Lofrano, G.; Grassi, M.; Notarnicola, M. Characteristics and adsorption capacities of low-cost sorbents for wastewater treatment: A review. Sustain. Mater. Technol. 2016, 9, 10-40.

55. Moreno-Castilla, C. Adsorption of organic molecules from aqueous solutions on carbon materials. Carbon 2003, 42, 83-94. [CrossRef]

56. Zhang, P.; Li, Y.; Cao, Y.; Han, L. Characteristics of tetracycline adsorption by cow manure biochar prepared at different pyrolysis temperatures. Bioresour. Technol. 2019, 285, 121348. [CrossRef] [PubMed]

57. Kim, J.E.; Bhatia, S.K.; Song, H.J.; Yoo, E.; Jeon, H.J.; Yoon, J.-Y.; Yang, Y.; Gurav, R.; Yang, Y.-H.; Kim, H.J.; et al. Adsorptive removal of tetracycline from aqueous solution by maple leaf-derived biochar. Bioresour. Technol. 2020, 306, 123092. [CrossRef] [PubMed]

58. Jiaxin, N.; Dongmei, L.; Wei, W.; Aiwen, W.; Jialin, J.; Jiayu, T.; Zipeng, X. Hierarchical defect-rich flower-like BiOBr/Ag nanoparticles/ultrathin $\mathrm{g}-\mathrm{C}_{3} \mathrm{~N}_{4}$ with transfer channels plasmonic Z-scheme heterojunction photocatalyst for accelerated visiblelight-driven photothermal-photocatalytic oxytetracycline degradation. Chem. Eng. J. 2021, 419, 129969.

59. Wei, M.; Binghua, Y.; Wen, Z.; Yangqing, H.; Yan, Y.; Jinfen, N. Fabrication of PVDF-based piezocatalytic active membrane with enhanced oxytetracycline degradation efficiency through embedding few-layer E-MoS 2 nanosheets. Chem. Eng. J. 2021, $415,129000$. 